\title{
TENUN LURIK DALAM KEHIDUPAN MASYARAKAT JAWA
}

\author{
Isbandono Hariyanto *)
}

\begin{abstract}
ABSTRACK
Weaving itself is generally defined as the process of making cloth by crossing threads vertically (lungsi) and horizontal (weft) using a loom.

There are dynamics in the presence of striated in the Java community weaving both from the technical aspects, form and function. The development of striated weaving in Java as a result of culture can not be separated from the various factors that accompany it. It is seen from the aspect woven fabric striated function in Javanese society today has been a shift from, it can be seen from the dynamics that occur in the presence of the Java community weaving striated striated fabric that is both profane and can also be magical.
\end{abstract}

\section{ABSTRAK}

Tenun sendiri secara umum diartikan sebagai proses pembuatan kain dengan menyilangkan benang secara vertikal (lungsi) serta horizontal (pakan) dengan menggunakan alat tenun.

Ada dinamika yang terjadi pada keberadaan tenun lurik dalam masyarakat Jawa baik itu dari aspek teknis, bentuk maupun fungsinya. Perkembangan tenun lurik di Jawa sebagai sebuah hasil budaya tidak lepas dari berbagai faktor yang menyertainya. Hal tersebut terlihat dari aspek fungsi kain tenun lurik dalam kehidupan masyarakat Jawa saat ini telah terjadi pergeseran dari, hal ini terlihat dari dinamika yang terjadi pada keberadaan tenun lurik dalam masyarakat Jawa kain lurik yang bersifat profan dan dapat pula bersifat magis.

\section{PENDAHULUAN}

Bagi masyarakat Jawa, di samping kain batik terdapat pula sebuah kain yang menarik untuk dicermati. Kain ini lazim disebut dan dikenal dengan nama kain tenun lurik. Kain tenun lurik ini memilki kekhasannya tersendiri. Secara visual kain tenun lurik merupakan kain dengan susunan unsur garis dan bidang yang bervariasi. Unsur garis dan bidang tersebut bukan semata hanya bertujuan untuk keindahan secara visual semata atau visioplastis semata, namun juga memiliki keindahan secara filosofis.

Artikel ini akan mereview kembali tentang keberadaan tenun lurik yang ada di Jawa. Pembahasan pertama adalah berkaitan dengan aspek teknis yang meliputi alat, bahan, dan teknik produksi tenun lurik. Aspek estetis dan filosofisnya akan menjadi bahasan berikutnya. Disajikan pula tentang ulasan berbagai

\footnotetext{
* Isbandono Hariyanto (hariyantoisbandono@ymail.com), Staf Pengajar Jurusan Kriya, Fakultas Seni Rupa Institut Seni Indonesia Yogyakarta.
} 
jenis kain tenun lurik masa kini yang memiliki aspek fungsi yang sudah dikembangkan mengikuti selera pasar dan semangat zaman modern saat ini.

\section{PEMBAHASAN}

\section{Alat, Bahan, dan Teknik Produksi Tenun Lurik}

Alat tenun yang digunakan dalam pembuatan kain tenun lurik pada awalnya masih menggunakan alat tenun yang sangat sederhana yaitu alat tenun gedhog atau genhong, dalam perkembangannya untuk mencapai hasil produksi yang lebih cepat para perajin tenun lurik beralih menggunakan Alat Tenun Bukan Mesin (ATBM) yang hingga saat ini masih dipertahankan sebagai alat pembuatan tenun lurik diberbagai daerah di Pulau Jawa (Isyanti, 2003: 18).

Bahan dasar yang dibutuhkan dalam pembuatan tenun lurik berupa benang yang terdiri dari dua macam, yaitu benang lungsi dan benang pakan. Benang lungsi yang biasa digunakan adalah berupa benang dalam wujud cones yang kemudian diolah dan dipersiapkan melalui proses penyetrèngan, pencelupan, dan pengelosan.

Penyetrèngan adalah mengurai benang dari bentuk cones kedalam bentuk strènk, hal ini dilakukan dengan tujuan agar dalam proses perwarnaan benang, zat warna dapat meresap dengan sempurna ke dalam benang (Widodo, 2008: 7). Proses pencelupan (pewarnaan) pada benang tenun dapat dilakukan dengan menggunakan bahan pewarna tradisional yang berasal dari bahan-bahan dan juga dapat menggunakan bahan-ahan pewarna sintesis yang memiliki aneka pilihan warna yang cukup banyak (Irawan, 2006). Proses pengelosan adalah menggulung benang dari bentuk cones, strènk, atau kelos ke dalam bobbin yang bertujuan untuk menyiapkan benang lungsi, sedangkan untuk menyiapkan benang pakan dilakukan dengan proses pemalètan, yaitu menggulung benang dalam bentuk cones ke dalam kleting.

Teknik produksi tenun lurik dapat dibagi menjadi tiga tahapan, yaitu persiapan, penyetelan, dan penenunan. Tahap persiapan ialah tahap mempersiapkan bahan dan alat sampai dengan tahap penyetelan alat hingga siap untuk pelaksanaan penenunan

Setelah memastikan penyetelan terlaksana dengan baik, maka tahap penenunan siap untuk dilaksanakan, menenun pada prinsipnya seperti juga menganyam benang lungsi dan benang pakan. Proses menenun merupakan sebuah proses yang mengulang-ulang gerakan (Marah,1989/1990: 26).

\section{Aspek Estetis dan Filosofis}

Tenun lurik merupakan salah satu wujud kekayaan budaya tradisional Jawa. Sebagai salah satu bentuk kain tradisional, tenun lurik bukan hanya berfungsi sebagai pakaian semata, namun juga memiliki nilai filosofis yang sangat penting bagi masyarakat sebagaimana diungkapkan oleh Risman Marah dalam buku Berbagai Pola Kain Tenun dan Kehidupan Pengrajinnya, bahwa masyarakat Jawa adalah masyarakat yang sangat kental dengan suasana hidup mistis yang dilatarbelakangi oleh kebudayaan Hindu yang melingkupinya di masa lampau. Penciptaan 
tenun lurik dilakukan bukan hanya untuk mengisi waktu luang yang setelah mereka panen dan menanami sawah-sawahnya kembali hingga menunggu masa panen berikutnya, akan tetapi lebih jauh lagi telah bersinggungan dengan kepentingan kepercayaan, perasaan sakral, dan pemuasan akan cita rasa keindahan. Tenun lurik juga penuh dengan semua makna, bermacam-macam corak dengan variasi warna yang berbeda mengandung makna yang telah digariskan menjadi sebuah patron corak. Patron tersebut adalah hasil karya para empu yang piawai yang di dalamnya telah disertakan seluruh cita rasa dan aspirasi kepentingan budaya masa itu (Marah,1989/1990:10-11).

Patron-paton dalam tenun lurik oleh masyarakat Jawa dianggap mempunyai kekuatan mistis, sehingga penggunaannya terbatas pada waktu dan kepentingan tertentu saja. Seperti corak liwatan, tumbar pecah, kembenan, dan nyampingan yang dipakai untuk upacara selamatan tujuh bulanan, corak pletek jarak yang khusus dipakai oleh para bangsawan yang dapat menambah kewibawaan pada pemakainya.

Tenun sendiri secara umum diartikan sebagai proses pembuatan kain dengan menyilangkan benang secara vertikal (lungsi) serta horizontal (pakan) dengan menggunakan alat tenun. Menenun adalah suatu cara membuat pakaian yang mempunyai prinsip-prinsip menjalin bagian-bagian yang lurus atau vertikal dengan bagian yang melintang atau horizontal (Kartiwa, 2000: 31). Lurik adalah tenun yang motifnya didominasi dengan lèrèk-lèrèk atau garis-garis. Corak garisgaris searah panjang sehelai kain disebut dengan istilah lajuran, dan yang searah lebar kain dan disebut pakan malang. Adapun corak kotak-kotak kecil disebut dengan istilah cacahan. Ketiga corak tersebut di Jawa khususnya Jawa Tengah dan Jawa Timur disebut sebagai lurik (Djoemena, 2000: 31).

Berbagai macam kain tenun yang ada di Indonesia antara lain ada yang disebut tenun lurik, tenun ikat, dan tenun songket. Salah satu hasil tenun yang sangat sederhana, baik dalam penampilan maupun dalam pengerjaannya adalah kain tenun lurik. Meskipun sangat sederhana namun kain lurik ini sarat dengan berbagai makna (Djoemena, 2000: 1). Kain lurik dalam istilah Jawa kuna disebut larik yang berarti baris, deret, garis, dan lajur (Zoetmulder, 1982: 575). Pendapat lain mengatakan lurik berasal kata rik yang berarti garis atau parit, yang dapat bermakna sebagai pagar atau pelindung bagi pemakainya (Anonim, 2004: 6). Sumber lain mengatakan bahwa motif tenun lurik yang berbentuk kotak-kotak merupakan inspirasi dari buah nangka yang belum matang (bahasa Jawa: gori) yang dicacah-cacah sehingga membentuk motif kotak-kotak yang dalam corak tenun lurik terdapat motif Cacah gori, atau Damdaman. (Martono, 1997/1998: 8)

Di Pulau Jawa khususnya di daerah Jogja dan Solo, kain lurik ditenun dengan teknik wareg yang berarti anyaman datar atau polos. Meski jika dilihat dari teknik pengerjaan sederhana, namun sesungguhnya dibutuhkan sebuah ketrampilan dan kejelian dalam memadukan warna serta tata susunan kota dan garis yang selaras dan seimbang agar 
menghasilkan kain lurik yang indah dan mengagumkan (e.artscraftindonesia.com), yang pada hakekatnya corak lurik secara garis besar dibagi dalam 3 corak dasar, yaitu corak lajuran, corak pakan malang, dan corak cacahan (Martono, 1997/1998: 6).

Corak lajuran, adalah corak lajur yang garis-garisnya membujur searah benang lungsi.

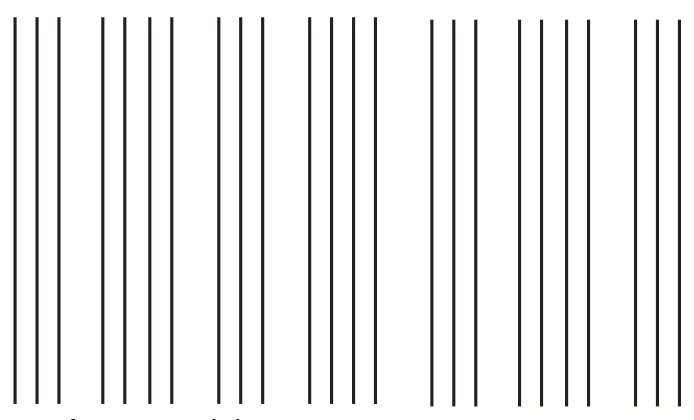

Gambar 1. Corak lajuran

Corak pakan malang, adalah corak di mana garis-garisnya melintang searah benang pakan.

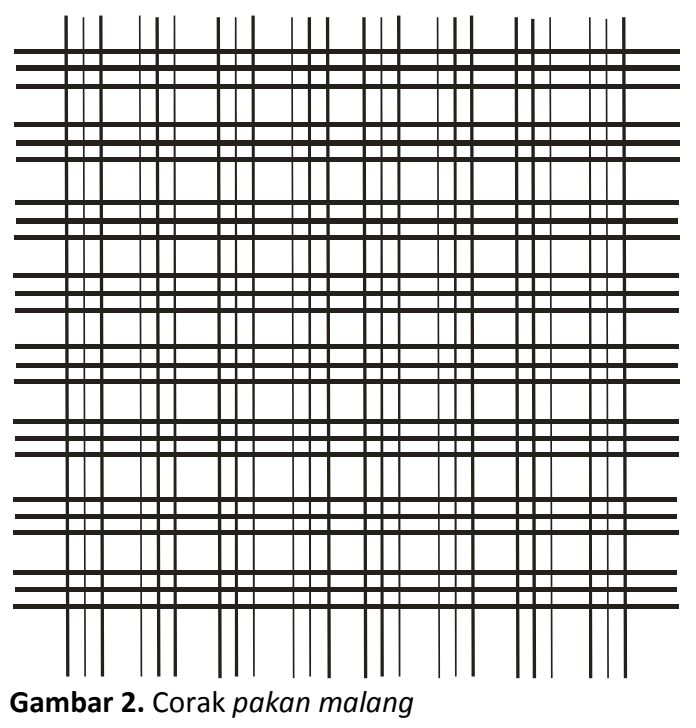

Corak cacahan adalah corak yang terjadi dari persilangan antara corak lajuran dan corak pakan malang.

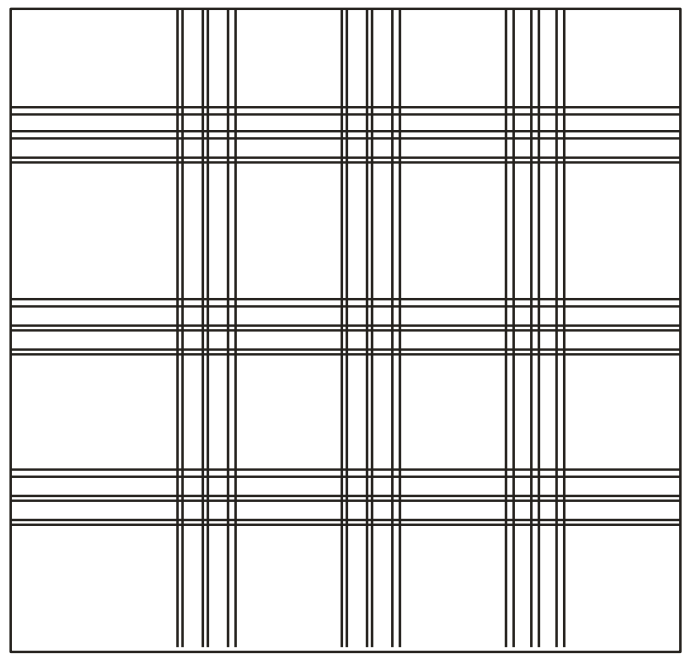

Gambar 3. Corak cacahan

Walaupun corak lurik hanya terdiri dari garis-garis dan kotak-kotak namun memiliki makna, tradisi, serta adat dan kepercayaan bagi masyarakat. Corak-corak tradisional memiliki nama-nama yang diambil dari nama flora dan fauna lingkungan sekitarnya yang memberi manfaat bagi mereka. Terdapat pula namanama yang diambil dari benda-benda yang dianggap sakral yang memberi berkah serta lindungan dari segala malapetaka, dengan istilah tolak bala.

Tenun lurik tradisional memiliki motif yang sangat beragam dan mempunyai makna simbolis. Terdapat pula motif-motif modern yang merupakan pengembangan dari motif yang telah ada terutama dari segi coraknya. Hal ini merupakan usaha yang dilakukan perajin untuk melakukan variasi-variasi dalam menciptakan corak garis.

Di Kecamatan Pedan Kabupaten Klaten Jawa Tengah, jenis corak tenun lurik tradisional yang masih dapat dijumpai dan dibuat oleh perajin antara lain adalah motif Tumenggungan, Bribil, Liwatan, Tumbar 
Pecah, Lasem, dan motif Telu Pat (Marah, 1989/1990: 12-13).

\section{Motif Tumenggungan}

Motif Tumenggungan pada awalnya hanya diperbolehkan dipakai oleh bangsawan kraton, khususnya seorang tumenggung yang dikeluarkan oleh Kraton Surakarta (Marah, 1989/1990: 12). Motif ini menurut pembagian corak dasar di atas termasuk ke dalam kategori corak pakan malang, yaitu corak garis-garis melintang searah benang pakan.

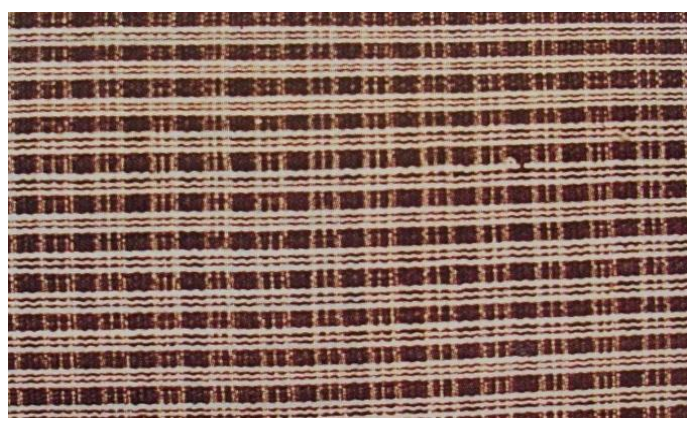

Gambar 4. Corak Tumenggungan

(Sumber: Djoemena, 2000)

\section{Motif Bribil}

Motif ini diciptakan pada masa pemerintahan Paku Buwono VI, di Kraton Surakarta dan hanya boleh digunakan oleh bangsawan Kraton (Djoemena, 2000: 48). Motif Bribil menurut pembagian corak dasarnya termasuk ke dalam corak lajuran, yaitu garis-garis benang terlihat jelas membujur searah benang lungsi. Motif ini memiliki tata susunan dan lebar lajur-lajur satuan kelompok yang sama, namun dengan perpaduan warna benang yang berbeda.

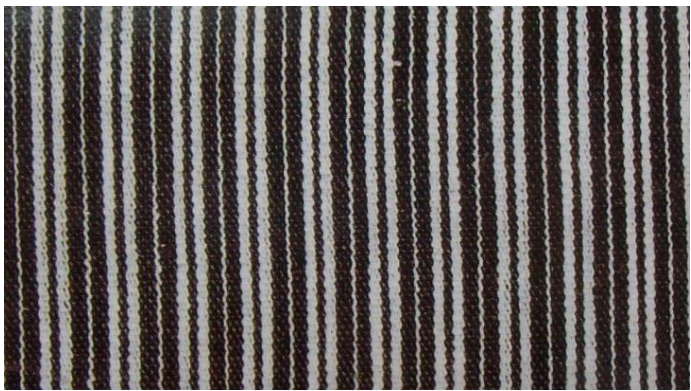

Gambar 5. Motif Bribil

(Sumber: Djoemena, 2000)

\section{Motif Liwatan}

Motif Liwatan menurut pembagian corak dasarnya juga termasuk ke dalam corak lajuran. Corak ini terdiri dari 3 bagian, di mana setiap bagian terdapat kelompok garis-garis lajur yang berbeda. Pada kedua sisi kain terdapat kelompok garis lajur yang mengapit pada kelompok garis bagian tengah yang memiliki tata warna yang berbeda dengan kelompok garis yang mengapitnya.

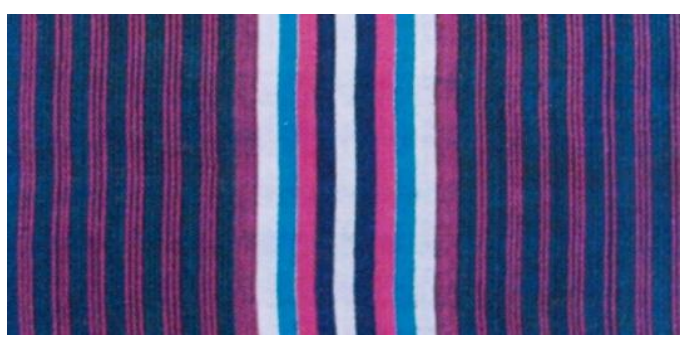

Gambar 6. Motif Liwatan

(Sumber: Djoemena, 2000)

Motif Tumbar Pecah

Motif ini menurut pembagian corak dasar yang ada termasuk ke dalam corak cacahan, yaitu corak yang terjadi merupakan persilangan antara corak lajuran dan corak pakan malang. 


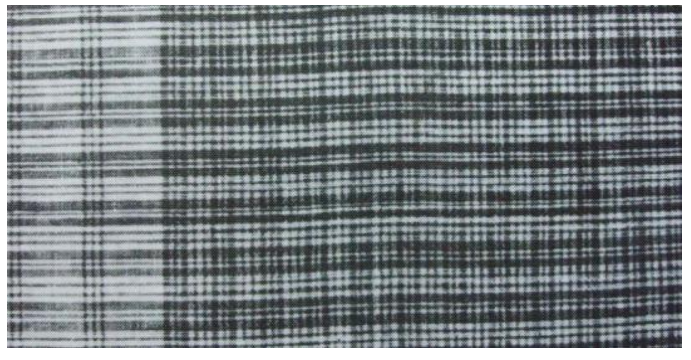

Gambar 7. Motif Tumbar Pecah

(Sumber: Djoemena, 2000)

\section{Motif Lasem}

Motif Lasem termasuk ke dalam corak lajuran dengan garis-garis lajur yang memiliki ukuran sama serta memiliki warna dasar yang sama. Dalam motif ini terlihat jelas adanya pakan malang yang berfungsi sebagai tumpal (Djoemena, 2000: 44-45).

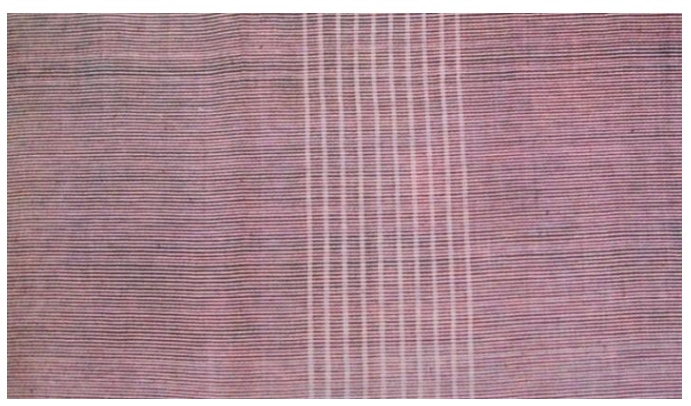

Gambar 8. Motif Lasem

(Sumber: Djoemena, 2000)

\section{Motif Telu Pat}

Motif Telu Pat atau disebut juga motif Pranakan adalah ciptaan Sri Sultan Hamengku Buwana V, yang idenya datang ketika berkunjung ke sebuah pesantren di Banten dan melihat para santri perempuan memakai baju kurung lengan panjang dengan lobang sampai bawah leher yang dibelah (Suwito,2009) Motif Telu Pat menurut pembagian corak dasarnya juga termasuk ke dalam corak lajuran, corak garis benang terlihat jelas membujur searah benang lungsi yang berjumlah tiga dan empat dan dengan warna dasar biru tua (Roedjito, 1985: 1)

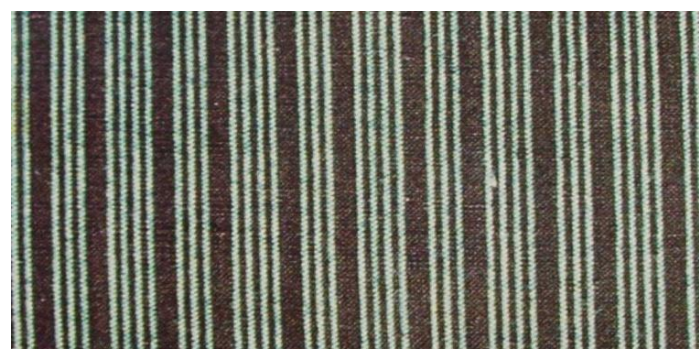

Gambar 9. Motif Telu Pat

(Sumber: Djoemena, 2000)

Adapun motif-motif tradisional yang telah mengalami pengembangan dari segi bentuk terlihat dalam garis lungsi, maupun pada benang pakan. Nama-nama yang diberikan berdasarkan dari gejala bentuk motifnya, nama-nama motif tersebut antara lain motif Kembang Gedhang, Yuyu Sekandang, Sada Saler, Sulur Ringin Abang, dan Mangkuratan (Marah, 1989/1990: 14).

\section{Motif Kembang Gedhang}

Menurut pembagian corak dasar motif Kembang Gedhang termasuk dalam corak lajuran, hal ini terlihat dari corak lajur garis-garis yang terlihat dominan membujur searah benang lungsi.

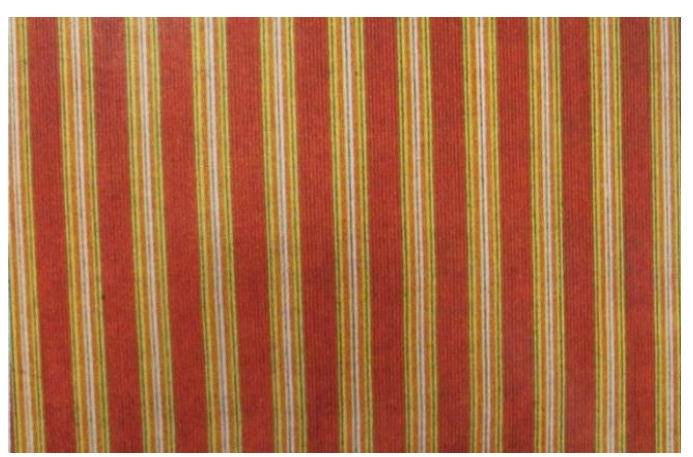

Gambar 10. Motif Kembang Gedhang

(Sumber: Djoemena, 2000) 


\section{Motif Yuyu Sekandang}

Motif ini menurut pembagian corak dasar yang ada termasuk ke dalam corak cacahan, yaitu corak yang terjadi merupakan persilangan antara corak lajuran dan corak pakan malang.

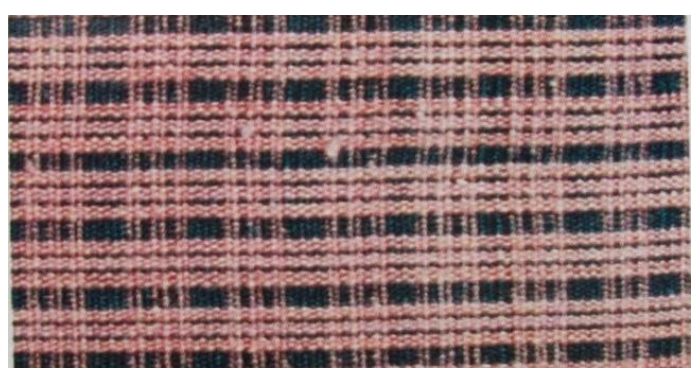

Gambar 11. Motif Yuyu Sekandang

(Sumber: Djoemena, 2000)

\section{Motif Sada Saler}

Menurut pembagiannya motif ini termasuk dalam corak lajuran. Hal ini dapat terlihat dari corak lajur garis-garis yang berbeda ukuran besarnya sehingga terlihat dominan garis-garis membujur searah benang lungsi.

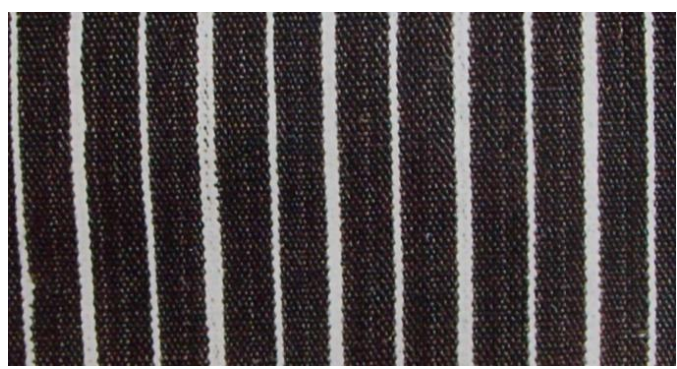

Gambar 12. Motif Sada Saler

(Sumber: Djoemena, 2000)

\section{Motif Sulur Ringin Abang}

Motif ini termasuk dalam corak lajuran, hal ini terlihat dari lajur garis-garis yang membujur searah benang lungsi dengan ukuran besar yang tidak sama.

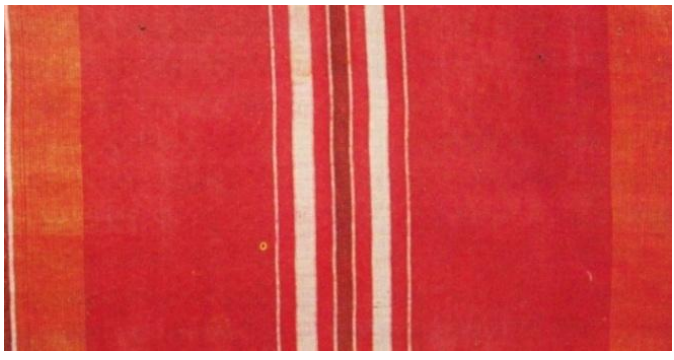

Gambar 13. Motif Sulur Ringin Abang

(Sumber: Djoemena, 2000)

\section{Motif Mangkuratan}

Motif Mangkuratan juga termasuk dalam dalam corak lajuran, hal ini terlihat dari corak lajur garis-garis yang terlihat dominan membujur searah benang lungsi.

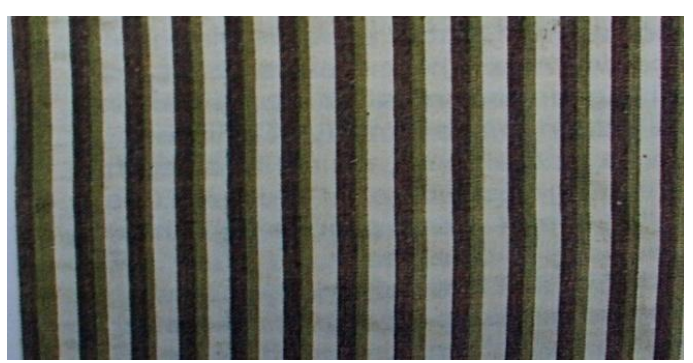

Gambar 14. Motif Mangkuratan

(Sumber: Djoemena, 2000)

\section{Tenun Lurik di Masa Kini}

Tenun lurik telah mengalami perkembangan sesuai dengan situasi dan kondisi yang ada. la tidak hanya berhenti pada satu titik saja melainkan juga bergerak dinamis baik dari aspek bentuk maupun fungsinya. Fungsi kain tenun lurik dapat bersifat profan dan dapat pula bersifat magis. Bersifat profan yaitu kain tenun yang dipakai untuk pakaian seharihari, hal ini sesuai dengan kehidupan masyarakat modern yang cendrung bersifat profan tanpa makna-makna simbolis, melainkan hanya untuk memenuhi selera pasar sebagai bahan komoditi. Sementara itu fungsi kain lurik yang berhubungan dengan nilai-nilai magis, spiritual, dan 
status simbol penggunaannya sering dipakai pada waktu upacara tertentu dan dengan motif-motif tertentu pula (Martono, 1997/1998: 6). Masyarakat modern memiliki pandangan dan persepsi yang berbeda dengan masyarakat tradisional. Hal inilah yang mengakibatkan adanya pergeseran bentuk dan fungsi dari kain tenun lurik itu sendiri. Bentuk dan fungsi kain lurik tidak hanya berhenti pada aspek tradisi semata namun juga ikut menyesuaikan dengan keadaan di masa sekarang.

\section{PENUTUP}

Ada dinamika yang terjadi pada keberadaan tenun lurik dalam masyarakat Jawa baik itu dari aspek teknis, bentuk maupun fungsinya. Perkembangan tenun lurik di Jawa sebagai sebuah hasil budaya tidak lepas dari berbagai faktor yang menyertainya. Hal tersebut terlihat dari aspek fungsi kain tenun lurik dalam kehidupan masyarakat Jawa saat ini telah terjadi pergeseran dari, hal ini terlihat dari dinamika yang terjadi pada keberadaan tenun lurik dalam masyarakat Jawa kain lurik yang bersifat profan dan dapat pula bersifat magis. Bersifat profan yaitu kain tenun yang dipakai untuk pakaian seharihari, hal ini sesuai dengan tata kehidupan masyarakat modern yang cenderung bersifat profan tanpa muatan makna simbolis di dalamnya, melainkan hanya untuk memenuhi selera pasar sebagai bahan komoditi. Demikian ulasan singkat artikel ini mudah-mudahan dapat memberikan gambaran dan wawasan yang terkait dengan kondisi dan keberadaan seni tenun lurik di Jawa dewasa ini.

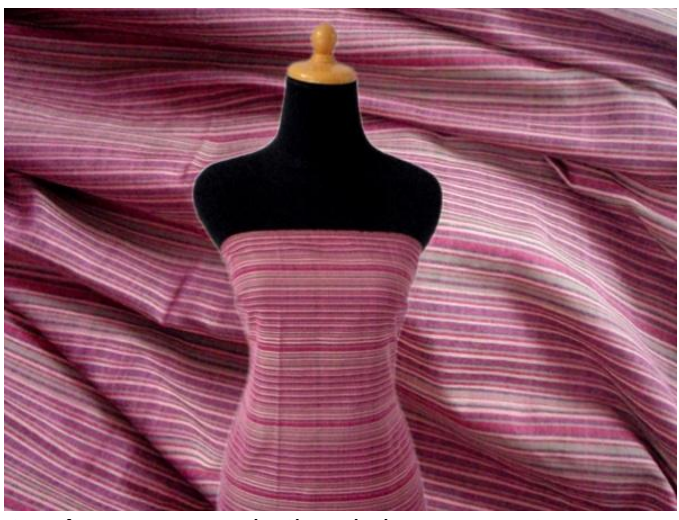

Gambar 15. Tenun lurik pada busana wanita (Sumber: www.tenunikat.com, 2012)

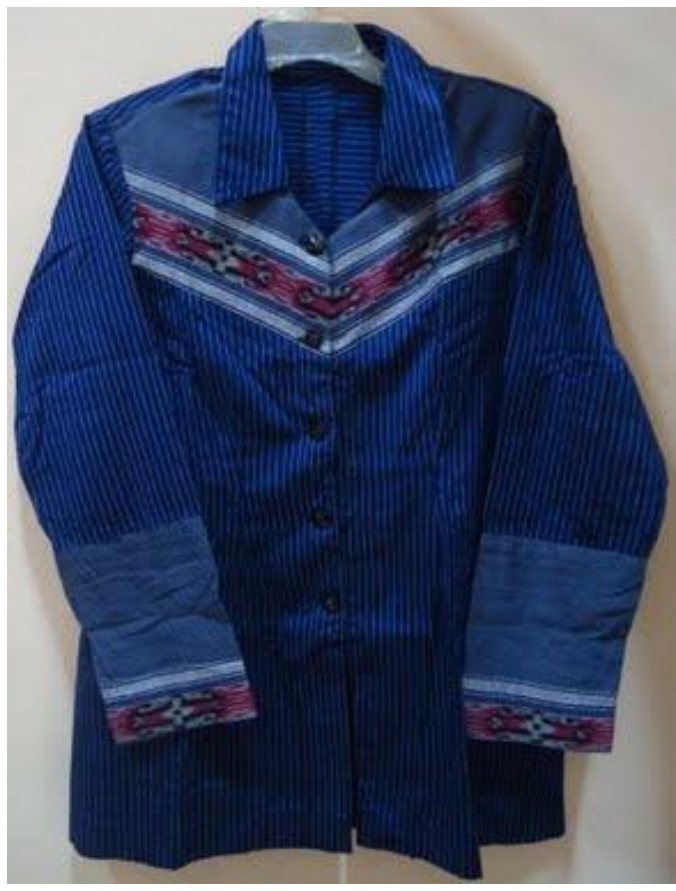

Gambar 16. Tenun lurik pada busana pria (Sumber: yenidaryono.blogspot.com, 2012)

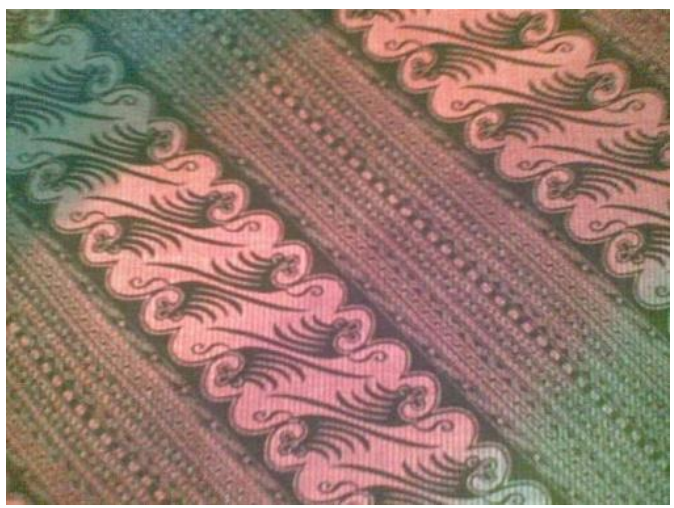

Gambar 17. Tenun lurik dengan kombinasi teknik batik

(Sumber: yenidaryono.blogspot.com, 2012) 


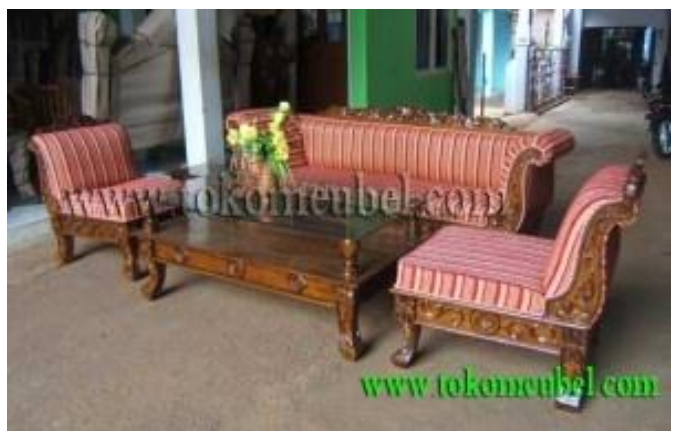

Gambar 18. Tenun lurik terapkan pada pelapis jok kursi

(Sumber: kampoeng_tenun@yahoo.com, 2012)

\section{DAFTAR PUSTAKA}

Djoemena, Nian S. Lurik: Garis-garis Bertuah: The Magic Stripes. Jakarta: Djambatan, 2000.

Ensiklopedi Nasional Indonesia jilid 9. Jakarta: PT. Delta Pamungkas, 2004.

Irawan, Lukfi. Pengetahuan Zat Warna Sintesis, Makalah disampaikan dalam Pelatihan Zat Warna Alam, Direktorat Industri Sandang Ditjen IKM Departemen Perindustrian, 2006

Isyanti, Sadilah, Herawati, Sumardi, Sunjata. Sistem Pengetahuan Kerajinan Tradisional, Tenun Gedhog di Tuban, Propinsi Jawa Timur. Yogyakarta: Kementrian Kebudayaan dan Pariwisata, Deputi Bidang Pelestarian dan Pengembangan Kebudayaan, Balai Kajian Sejarah dan Nilai Tradisional Yogyakarta, Proyek Pemanfaatan Kebudayan Daerah, Daerah Istimewa Yogyakarta, 2003.

Kartiwa, Suwati. Tenun Ikat: Indonesian Ikats. Jakarta: Djambatan, 1987.
Marah, Risman. Berbagai Pola Kain Tenun dan Kehidupan Para Perajinnya. Jakarta: Departemen Pendidikan dan Kebudayaan, 1990.

Martono, Kain Tenun: Koleksi Museum Sono Budoyo. Yogyakarta: Museum Negeri Propinsi D.I. Yogyakarta Sonobudoyo, 1997/1998.

Roedjito, Tenun Lurik Tradisional (TenunGendhong). Yogyakarta: Bagian Koleksi Musiun Sonobudoyo Yogyakarta, 1985.

Widodo, Suryo Tri, "Produksi Tenun ATBM Dengan Aplikasi Dan Variasi Pakan Non Benang, dalam ARS, Jurnal Seni Rupa dan Desain No. 09/ Sep-Des. 2008.

Zoetmulder, P.J. Kamus Jawa KunoIndonesia, Bagian I. Jakarta: Perwakilan Koninlijk Instituut voor Taal-, land-,en volkenkunde dan PT. Gramedia Pustaka Utama, 1982.

www.e.artscraftindonesia.com www.kampoeng_tenun@yahoo.com. www.yenidaryono.blogspot.com. www.tenunikat.com, 